\title{
A Proposed Training Program for Treating Aloud Reading Errors Among Students With LDS in Aseer Region
}

Mohammed Ali Hussain Al Khammash

Article History:

Received 16.12.2020

Received in revised form 01.08.2021

Accepted

Available online

01.10.2021

\begin{abstract}
The current study addressed the errors in reading aloud among students with learning disabilities at the elementary level in Aseer region, Saudi Arabia. The study proposed a training program to treat errors of reading aloud among students with LDs after identifying these errors and exploring the impact of the training program on the students. The study used the experimental approach by designing a training program to address the errors in reading aloud. The sample of the study consisted of two students with LDs. Each student was assigned to a group, an experimental and control. After completing the treatment program, the student was fluent in pronouncing letters from their correct articulations without substitution or repetition. The student mastered the distinction between different acoustic phenomena such as stress and joining. After completing the treatment program, the student was fluent in pronouncing words and sentences with ease and integrity, with correct pronunciation in terms of structure and syntax. The study recommends using the training program to treat errors in reading aloud among students with LDs
\end{abstract}

(C) IJERE. All rights reserved

\section{INTRODUCTION}

Keywords: Reading aloud, students with LDs, reading skills, Saudi Arabia

Reading is a distinguished linguistic activity in human life, as it is an important means of communication and forms a window through which the individual overlooks various knowledge and cultures (Karagoz, 2021). It is also an important factor in personality development. Reading is a method of communication and scientific development. Through reading, the individual's needs, thoughts, and emotions, are met and it enriches the individual's experiences by providing him with ideas, opinions, and experiences. Reading also helps the individual to embark on continuous education, which has become a necessity to keep pace with current development. Reading cannot be overlooked, as it is the most important skill that a person learns, and it is the basis on which the student relies in understanding and acquiring linguistic skills. It is a means of understanding and achieving various school subjects because it depends on the reading process. The student who possesses reading skills and excels in them can excel in other school subjects. On the other hand, for students who are unable to possess reading skills, it is expected that they will suffer academic failure in other school subjects (Hariyani, Ahmad \& Marsitin,2021).

Reading aloud is considered the best way to diagnose reading errors, and to detect defects and difficulties that hinder reading fluency. In this way, the teacher can identify reading errors in pronouncing words during reading, such as replacing a letter with another letter, deleting some letters, adding them, or stopping wrongly while reading frequently. This leads to the repetition of some words or phrases or jumping from one line to another. Through reading aloud, we can follow the reader's commitment to punctuation. The current reality indicates that there is a weakness in the performance of basic stage students in reading aloud, which may reflect the teachers' lack of knowledge of the strategies that can be employed in treating this weakness among students. In addition, some teachers may misunderstand the reading process and its required skills. They understand the reading process as transforming the written symbols into spoken words, without focusing on reading comprehension, which is the main goal of the reading process and is the desired result of it (Muza,2021). This misunderstood concept led to the existence of weak students in reading, who are unable to decode the written text and understand it fully. Therefore, the current study addresses the problem of weakness in reading aloud after identifying the common mistakes of these students.

It is clear from the above that reading aloud is important for students. Therefore, it is essential that the skills of reading aloud be present in the curriculum and the classroom because of the importance it represents in linguistic communication, and understanding the linguistic message between the writer and the reader. The problem of the current research is that there are errors in reading aloud among students with learning disabilities in the elementary stage, which prevents them from benefiting from educational programs at the same level as their ordinary peers. Therefore, the current study seeks to present a suggested program to treat errors of reading aloud among students with learning disabilities in elementary schools in Aseer region in Saudi Arabia.

This study aims at achieving the following objectives:

After completing the treatment program, the student to be fluent in pronouncing letters from their correct articulation without substitution or repetition.

After completing the treatment program, the student to master the distinction between different phonetic phenomena such as stress and joining. 
After completing the treatment program, the student to be fluent in pronouncing words and sentences with ease and integrity, pronouncing correctly in terms of structure and syntax.

After completing the program, the student to be able to control the words that he reads correctly.

The present study seeks to give answers to the following research questions:

1.What are the common errors students make during reading aloud?

2.Are there statistically significant differences between the scores of the experimental group and the control group in the post-test for reading aloud due to the training program?

The significance of this study stems lies in the problems students with learning disabilities face in the skills of reading aloud, which has negative effects on the nature of their adaptation in school and keeping pace with their ordinary peers at the level of academic achievement. The results of the study could help teachers and educators to use better techniques to treat errors in reading aloud among students with LDs.

There are several limitations to the generalization of the results of this study, such as the time limitations, as the study was conducted in the second semester in 2020. The study was applied in Aseer region in Saudi Arabia. The thematic limitations included tackling the topic of suggesting a training program to treat the errors in loud reading. The study was only applied to fourth-grade students with LDs.

\section{Literature Review}

There are many definitions of reading aloud. Some scholars defined it as "the shape of the letter and the word and mastering the skills of pronouncing them correctly, with the ability to vocalize the meanings and how to accent and intonate, and that the reciter's voice carries the meanings indicated by the punctuation marks" (MAl-Naqa and Hafez, 2006). Beja (2010) defined reading as a process of recognizing letters and words and pronouncing them. A good reader can pronounce written words well, free of errors. This concept directed studies and research to the physical aspects related to reading such as eye movements and speech organs.

Reading is defined as a mental psychological process that includes the ability to convert written symbols into spoken symbols. Reading is one of the basic psychological processes that require several mental processes necessary for their emergence. It is also one of the basic skills that make up the cognitive dimension for the child, and a major goal of the learning process. Reading is divided into silent reading and aloud reading (AlWaqfi, 2015).

Reading aloud is one of the basic language arts that have received great attention from researchers in language education and exceeded their interest in the rest of the other language arts, including listening, speaking, and writing. The source of that interest is their feeling of the importance of reading aloud and the greatness of its significance in people's lives throughout the ages (Yunus, 2015).

Reading skills

Recognition skills are the first step in learning to read, and they are - as well - one of the most important skills that the reader needs. The reader must be able to connect between symbols and their sounds to perform correctly in reading. These words often have connotations known to the learner and related to his environment and his life that he experienced before coming to school (Ahmed, 2015).

Another important skill is comprehension, which is one of the skills that the student should master. Comprehension means understanding the ideas presented by the writer. The written symbol carries a message and defines the feelings and emotions. The mere pronunciation of the symbol without understanding is not useful. However, pronouncing the symbol should be a way to recognize the ideas behind it. In this way, reading becomes a means of communication with others. The importance of understanding is evidenced by the fact that reading is an important medium for broadening the intellectual horizons of the young person, as well as the skill of comprehending reading enables the reader to benefit from the knowledge of civilizations (Yunus, 2015).

Expressive performance skills and fluency is another important skill. Performance is the use of physical expressions that help to understand the meaning during reading, and the representation of the phonological performance of different methods that help to understand the meaning, and the diversification of the phonemic layers.

Previous Studies

Al-Noor (2019) identified the difficulties of learning to read aloud among female students of grades four and five in the elementary stage in Al-Ahsa governorate and their relationship to the socio-economic situation of the family. The study sample was (73) female students. The researcher applied a questionnaire on the difficulties of learning to read aloud among students, in addition to a questionnaire for estimating the socio- 
economic status of the family. The results showed that the prevalence of difficulties in learning to read aloud reached $(20 \%)$, and that the degree of prevalence of difficulties in learning to read aloud is above average. In addition, there were no statistically significant differences in the difficulties of learning to read aloud according to the grade (fourth/fifth), or according to the order of birth of the student in her family. The results showed that there is no correlation between the learning difficulties of reading aloud among students of the fourth and fifth grades of elementary school with age level, or with the socio-economic level of the family. Mohammad (2019) drew a map for learning Arabic in high schools and vocational schools in Malang Regency in Indonesia. The study population consisted of (183) high schools and vocational schools, (12) schools were taken as a sample that was selected using the cluster sample. Data were collected using questionnaires that were filled out by Arabic language teachers in all sample schools. Data analysis was conducted and this study found that all Arabic language teachers in senior secondary schools and vocational schools in Malang Regency have a standardized Arabic teacher qualification in the school. Al-Sarrahin (2019) identified the skills of reading aloud necessary for students of the lower basic stage, and the degree to which students of this stage in the Al-Hasa district schools could have some of these skills. The study sample consisted of (345) male and female students distributed among seventeen classes in nine schools. The study tool consisted of a list of suitable reading skills for elementary school students and a notecard for the performance of students in the lower elementary stage of some skills of reading aloud. The researcher put the names of the study sample, and then put a mark in the box for the skill that he/she had mastered to determine the percentage of students' proficiency in skills. The study also used an audio recording of the students' readings, for easy reference, and to ensure the consistency of the analysis by re-listening to these recordings later. The study concluded with a set of necessary skills for third-grade students, and the study also found that the majority of students were at a weak level in the literacy skills that were studied. Makhoul (2019) investigated the intervention program's contribution to enhancing knowledge of Arab academic vocabulary and reading comprehension skills among Arabic-speaking seventhgrade students. The sample of this study consisted of (247) students from four schools in northern Palestine. The units targeted academic vocabulary and reading comprehension skills. To assess the effectiveness of the intervention program, academic vocabulary tests, as well as reading comprehension tests, were conducted. This study concluded that the intervention group showed significantly higher performance in reading comprehension and productive academic vocabulary when compared to the control group. In contrast, no significant improvement was observed in the acceptance of academic vocabulary knowledge. The results of the study indicated the contribution of comprehensive and direct educational curricula for academic vocabulary in enhancing knowledge of academic vocabulary and understanding of reading academic texts. Salem (2020) determined the effectiveness of training in phonemic awareness skills in treating aloud reading difficulties (phonological disorders) among primary school students with learning difficulties to read. The study used three measurement tools: the vocal disturbance notecard, the vocal reading skills notecard, and the scale of appreciation of aloud reading skills. The research sample consisted of (36) students with learning difficulties reading in the third grade of the elementary stage. The results indicated that the training unit on phonemic awareness skills was effective in developing the skills of reading aloud (treatment of vocal disorders among primary school students with difficulties). The training was effective in detail in developing the skills of reading aloud among primary school students with reading difficulties. Nguyenm (2020) explored the role of beneficial, critical, and aesthetic reading situations in engaging students in academic reading at the university and the extent to which these reading situations can be linked to enhancing student learning through academic reading. Using this dynamic view of reading, the study examined insights and evidence from recent research to investigate the relationship between these reading situations and student learning. The analyzed studies point to elements of the machine, critical, and aesthetic reading in curricula that effectively engage learners in academic reading. These reading methods relate to reinforcement learning in terms of individual reflexology, disciplinary engagement, social perspective, and global awareness. In this study, the researchers conducted a literature review and analysis approach by investigating advocates of using a variety of text types, giving students choice of texts, explicitly teaching dynamic reading skills, providing opportunities for social reading practices, and implementing process-based assessments for learning. The study found that these practices could reduce the burden of academic reading by enhancing participation and learning disciplinary knowledge. It is noted that most of the previous studies dealt with reading disabilities, and there are only a few studies according to the researcher's knowledge that has dealt with the subject of reading aloud. This indicates the necessity and importance of conducting more studies and research on the 
difficulties of reading aloud, especially in Aseer region. Within the limits of the researcher's knowledge of previous studies, he found that these studies are a good direction to the researcher in formulating the problem of the study, formulating its concepts appropriately, defining its objectives, formulating the study questions, and identifying its most important indicators, and determining the methodological strategy for the study. The researcher used the information the previous studies have in the theoretical framework and in building the proposed training program. The researcher benefited from previous studies in a lot of valuable information, especially as they dealt with the same topic, but with a different vision.

\section{Research Methodology}

This section provides information on the methodology of the present study, which includes population and sample, research instrument, and validity and reliability of the instrument.

Population and Sample

The study population consisted of all (615) students of the fourth grade of the elementary school in Sarat Abidah governorate for the academic year 2020-2021 according to the statistics of the Education Department in Sarat Abidah, distributed among (45) schools. The study sample consisted of (2) students due to the circumstances of the Corona pandemic and based on the instructions of the supervisor, Dr. Muhammad Mustafa. The school closure prevented from obtaining more members to the sample of the study.

Table 1. Distribution of the study sample according to the schools

School name Gender Number

\begin{tabular}{llll}
\hline $\begin{array}{l}\text { El Radwan } \\
\text { school Elementary }\end{array}$ & Male & 1 \\
$\begin{array}{l}\text { Obaida bin } \\
\text { Elementary School }\end{array}$ & Jarrah & Male & 1 \\
\hline Total & & 2 \\
\hline
\end{tabular}

\section{Research Instrument}

The study used a proposed educational program as an instrument. The program was applied to the sample to treat the errors in reading aloud. The program was built after reviewing the related literature and previous studies.

Each of the three levels of the program included two units, each unit comprising the following:

Reading texts chosen from the Arabic language curricula.

Questions about the reading text that measure reading skills, such as understanding, distinguishing, deduction, analysis, criticism ... etc.

Exercises following the questions. These exercises were varied and graded, and the aim of them was to train students on a range of reading skills, such as recognizing the meanings of vocabulary, or differentiating between vocabulary similar in shape and different in meaning within different sentences, or exercises asking the student to identify errors in reading when reading it. It also contains the error and then correcting it ... etc.

A set of activities that followed the exercises. The aim was to diversify the methods of achieving the main goal of the program, which is to improve reading among students and to move away from routine, such as visiting the library or getting to know what a group of pictures represents.

To verify the validity of the proposed educational program, the researcher presented this program in its initial form to a panel of qualified judges in the field of education. In light of the observations made by the judges, the necessary modifications were made and the program was designed in its final form.

\section{Results and Discussion}

Results of the first question: "what are the common errors students make during reading aloud?"

Students' errors were classified into three types: deletion, substitution, and addition, according to the diagnostic test. Table 2 includes the number of errors and their percentages of the study sample.

Table 2. The number of students' errors in reading aloud and their percentages 


\begin{tabular}{lcccccc}
$\begin{array}{l}\text { Type of } \\
\text { error }\end{array}$ & \multicolumn{2}{c}{ deletion } & \multicolumn{3}{c}{ addition } & \multicolumn{3}{c}{ substitution } \\
\hline Students & $\begin{array}{l}\text { Error } \\
\text { amount }\end{array}$ & percentage & $\begin{array}{l}\text { Error } \\
\text { amount }\end{array}$ & percentage & Error & percentage \\
Student 1 & $\% 68$ & 329 & $\% 12$ & 56 & $\% 20$ & 97 \\
Student 2 & $\% 76$ & 343 & $\% 10$ & 54 & $\% 14$ & 77 \\
\hline
\end{tabular}

Table (2) shows that the errors of the substitution type were the most common mistakes made by students. The percentage of the second student was $76 \%$, while the first student had the lowest percentage in this type of error, and it was $68 \%$. Errors of the type of deletion came after the substitution in their percentages. The highest percentage of them was for the first student and represented $20 \%$ of the total errors, and the percentage of errors for the second student was $14 \%$. The errors of the addition type were higher for the first student, representing $12 \%$, while it was for the second student $10 \%$.

Results of the second question: "Are there statistically significant differences between the scores of the experimental group and the control group in the post-test for reading aloud due to the training program?"

To answer this question, the mean scores and standard deviations of the experimental and control groups were calculated for children enrolled in the resource rooms for the pre and post-tests, and Table (3) illustrates the results.

Table 3. The mean scores and standard deviations of the students enrolled in the resource rooms on the pre and post-reading skills test according to the group variable

\begin{tabular}{lccccc} 
& & \multicolumn{2}{c}{ Pre-test } & \multicolumn{2}{c}{ Posttest } \\
\cline { 3 - 6 } Group & No. & Mean score & $\begin{array}{c}\text { Standard } \\
\text { deviation }\end{array}$ & Mean score & $\begin{array}{c}\text { Standard } \\
\text { deviation }\end{array}$ \\
experimental & 2 & 27.92 & 5.827 & 51.55 & 3.699
\end{tabular}

It is noted from Table (3) that the mean scores of the experimental group on the pretest was (27.92), while the mean scores of the members of the experimental group on the post-test was (51.55). The mean score of the control group on the post-test was (44.18).

The results of the study revealed that the error of the substitution type was the most common mistake of the study sample. The error of the omission type came after the substitution in the percentage of its prevalence in students' readings. The addition type was the least common type of error in student readings. The results of the current study are consistent with the results of previous studies (Al-Sarrahin, 2019; Makhoul, 2019; Salem, 2020; Nguyenm, 2020; Al-Nour, 2019 and Mohammad, 2019). Studies have shown that the number of eye movements during reading varies in a single line according to different individuals, the type of material being read, the type of reading, the growth of the reader, and the condition of the eyes. All these factors are related to the substitution type of errors. The incompatibility between eye movement on the lines of the read text and mental perception leads to this kind of error, as speed in reading denies this compatibility, as well as the increased self-confidence that appears among students of advanced grade levels. Reading aloud is audible and is between a group in most cases, so the reader tries to leave a good impact for the listeners on his reading ability. In this type of reading - reading aloud - the reader uses looking in addition to uttering the symbols in an audible voice to the group of listeners, as well as understanding what he is reading so that he can represent the meaning correctly, such as questioning or wondering. The reader does more than one task simultaneously, which requires him to find a fit between them, and it requires flexibility that leads him to the stage of mastery. Recommendations

In light of the results of this study, the researcher recommends the application of the suggested program to address students' mistakes in reading aloud. It is important to prepare training courses to familiarize male and female teachers with the latest findings of studies related to reading to employ them in educational situations. Teachers should be provided with methods to diagnose students' weaknesses in reading. Teachers should understand the correct reading aloud, realize its modern and real concept, not focus only on pronunciation, and neglect other skills related to it. The practice of reading aloud is not limited to the classroom only, but rather it must go beyond that to other situations in life such as school broadcasting, speeches, and poems at celebrations and festivals ... etc. the study also recommends conducting such a study in other areas, and comparing the results. 


\section{References}

Ahmed, A. (2015). The child and reading problems. 6th Edition, Beirut: The Egyptian Lebanese House. Ahsanuddin, M., Ainin, M., \& Asrori, I. (2019). The mapping of Arabic language learning in senior high schools and vocational schools in Malang regency. Arabiyat: Jurnal Pendidikan Bahasa Arab dan Kebahasaaraban, 6(1), 18-35.

Al Waqi, R. (2015). Learning difficulties theory and practice. Amman, Dar Al Masirah for printing, publishing and distribution.

Al-Beja, A. H. (2010). Fundamentals of teaching Arabic between theory and practice (lower stage). Amman: Dar AlFikr.

Ali, A. S. (2016). Mistakes of reading aloud in Arabic for Malay-speaking students: An analytical descriptive study. Journal of Linguistic and Literary Studies, 7, 5-26.

Al-Naqa, M. \& Waheed, H. (2006). Teaching Arabic language in public education, its entries and techniques. Faculty of Education Journal, Ain Shams University.

Al-Noor, L. N. (2019). Difficulties in learning to read aloud among students of fourth and fifth grades of elementary school in Al-Ahsa Governorate and their relationship to the socio-economic situation of the family. Journal of Educational and Psychological Sciences, 20(3), 169-209.

Al-Sarrahin, A. N. M. (2019). A degree of mastering some oral reading skills by students of the lower basic stage in Al-Hasa schools. Journal of Educational Sciences, 31 (2), 291-311.

Al-Sayed, I. (2020). The effectiveness of training in vocal awareness skills in treating vocal reading difficulties and vocal disorders for elementary pupils. Arab Studies in Education and Psychology, 117, $23-70$.

Hariyani,S. Ahmad,N.J.\&Marsitin,R. (2021). Mathematics teaching practicum for junior high school in a different culture-based situation. The Universal Academic Research Journal,3(2),77-86.

Karagöz,S. (2021). Evaluation of distance education: The sample of guidance and counseling students. The Universal Academic Research Journal,3(1),18-2.

Makhoul, B., \& Sabah, K. (2019). Academic vocabulary knowledge and reading comprehension skills among seventh-graders in Arabic as L1. Journal of psycholinguistic research, 48(4), 769-784.

Muza,S.H.(2021). Team teaching approach on academic performance of students in faculty of education. The Universal Academic Research Journal,2(2),58-63.

Nguyen, H. T. T., \& Henderson, A. (2020). Can the reading load be engaging? connecting the instrumental, critical and aesthetic in academic reading for student learning. Journal of University Teaching and Learning Practice, 17(2), 6.

Novita, S., Uyun, Q., Witruk, E., \& Siregar, J. R. (2019). Children with dyslexia in different cultures: Investigation of anxiety and coping strategies of children with dyslexia in Indonesia and Germany. Annals of dyslexia, 69(2), 204-218.

Rehab, A. A. (2018). Obstacles to teaching aloud reading at the primary level. Journal of Educational Sciences, 2, 226-249.

Shaker, H. and Mohi, Z. (2016). Evaluating the performance of female students of the first intermediate grade in reading aloud. Journal of Educational and Psychological Researches, 13, (49).

Vaughn, S., Solís, M., Miciak, J., Taylor, W. P., \& Fletcher, J. M. (2016). Effects from a randomized control trial comparing researcher and school-implemented treatments with fourth graders with significant reading difficulties. Journal of Research on Educational Effectiveness, 9(Suppl 1): 23-44.

Wanzek, J., Petscher, Y., Al Otaiba, S., Kent, S. C., Schatschneider, C., Haynes, M.,... \& Jones, F. G. (2016). Examining the average and local effects of a standardized treatment for fourth graders with reading difficulties. Journal of Research on Educational Effectiveness, 9,45-66.

Yunus, F. A. (2015). Reading and knowledge. Egyptian Association for Reading and Knowledge. 